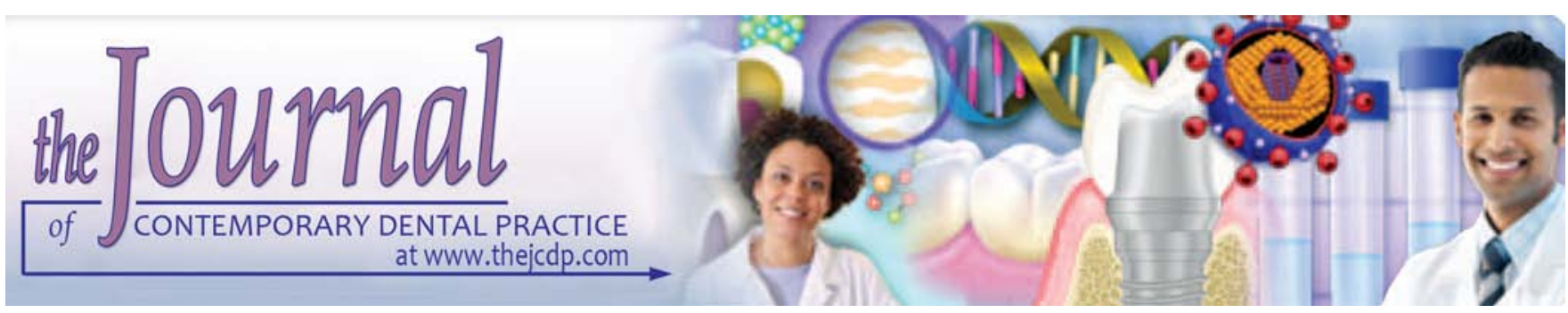

\title{
Evaluation of Fracture Resistance of Orthodontic Mini-implants in the Transmucosal Profile Region
}

\author{
${ }^{1}$ Arilton Mota de Aguiar, ${ }^{2}$ Fausto Silva Bramante, ${ }^{3}$ Adelson Mota de Aguiar, ${ }^{4}$ Célia Regina Maio Pinzan-Vercelino
}

\begin{abstract}
Aim: This study sought to compare the fracture resistance of three trademarked orthodontic mini-implants in the transmucosal profile region. Thirty-six mini-implants of three different brands, separated into groups I, II and III, were tested. Each group consisted of 12 mini-implants of $6 \mathrm{~mm}$ in length. The mean diameter and length of the transmucosal profile of the mini-implants were 1.90 and $2.0 \mathrm{~mm}$ in group I, 1.77 and $1.0 \mathrm{~mm}$ in group II and 1.50 and $1.0 \mathrm{~mm}$ in group III, respectively. The tests were performed on a universal testing machine in compression mode, with a 2,000 kgf load, a speed of $4.0 \mathrm{~mm}$ per minute and a chisel-shaped active tip, which acted crosssectionally on the transmucosal profile. Single-criterion analysis of variance was used to compare the three brands. A significance level of $5 \%$ and test power of $80 \%$ were adopted. The mean fracture resistance achieved by the mini-implants was $172.03 \pm 25.59 \mathrm{~N}$ for group I, $162.35 \pm 30.81 \mathrm{~N}$ for group II and $139.69 \pm 42.99 \mathrm{~N}$ for group III. There was no statistically significant difference in mean fracture resistance among the tested mini-implant brands.
\end{abstract}

Conclusion: The transmucosal profile diameter does not seem to be a deciding factor in the choice of mini-implants to minimize the risk of fractures.

Clinical significance: Although being an in vitro study it is possible to believe that this new brand has a very satisfactory resistance to fracture and enables its use with great efficiency.

Keywords: Orthodontic anchorage procedures, Tooth movement, Orthodontic appliances.

How to cite this article: de Aguiar AM, Bramante FS, de Aguiar AM, Pinzan-Vercelino CRM. Evaluation of Fracture Resistance of Orthodontic Mini-implants in the Transmucosal Profile Region. J Contemp Dent Pract 2015;16(5):372-375.

Source of support: Nil

Conflict of interest: None

${ }^{1-4}$ Department of Orthodontics, CEUMA University, São Luís Maranhão, Brazil

Corresponding Author: Fausto Silva Bramante, Assistant Professor, Department of Orthodontics, CEUMA University São Luís, Maranhão, Brazil, 65075-120, e-mail: faubramante@ hotmail.com

\section{INTRODUCTION}

The malocclusion is frequently observed in different populations, and can be characterized by many anomalies. ${ }^{1}$ For proper treatment, the modern orthodontics has evolved apace, with materials and techniques providing increasingly efficient orthodontic treatments. In this respect, one of the innovations that stands out most is the introduction of the mini-implant, a device that has a simple installation and removal technique and is easy to use, although its use can cause complications. ${ }^{2-5}$

Mini-implants have created new possibilities for orthodontic treatment, especially with regard to anchoring. ${ }^{2,3}$ However, faults (such as fracture) can occur in their use during any treatment phase, with insertion and removal representing critical points in the process. ${ }^{4-16}$ The incidence of fractures at the time of insertion is approximately $4 \%,{ }^{10}$ and because they also present plastic deformation, mini-implants are also subject to fracture under bending loads. ${ }^{17}$

Fractures typically occur in the transmucosal profile, i.e. the area between the head and body of the miniimplant that endures a high amount of stress. ${ }^{17,18}$ When mini-implant fracture occurs, surgery is required to remove the fractured intraosseous portion and replace it with another mini-implant with a new reinsertion. This complication leads to increased treatment time and costs in addition to patient dissatisfaction.

The objective of this study was to compare the fracture resistance of three commercial brands of orthodontic mini-implants in the transmucosal profile region, as that location of the mini-implant where most fractures occur. ${ }^{2,4,17,18}$

\section{MATERIALS AND METHODS}

Thirty-six self-drilling orthodontic mini-implants of three trademarks were used in this study. All implants 
were produced in titanium alloy Ti6Al4V to the ASTM F136 standard, ${ }^{19}$ according to the manufacturers' specifications. Three groups of 12 mini-implants were created, each corresponding to one brand. Mini-implants produced by the company 'Morelli' (Dental Morelli LTDA-Sorocaba/SP, Brazil) were assigned to group I; mini-implants made by the 'SIN' factory (Sistema de Implante Nacional-São Paulo/SP, Brazil) were assigned to group II; and mini-implants manufactured by the 'Conexão' industry (Conexão Sistemas de Prótese LTDAArujá/SP, Brazil) were assigned to group III (Fig. 1).

The mean diameter of the transmucosal profile of the mini-implants was $1.90 \mathrm{~mm}$ for group I, $1.77 \mathrm{~mm}$ for group II and $1.50 \mathrm{~mm}$ for group III. The characteristics, references and manufacturing batches of the miniimplants are described in Table 1.

Each mini-implant was embedded in auto polymerizing acrylic resin (Jet-Artigos Odontológicos Clássico LTDA - Campo Limpo Paulista/SP, Brazil) within a cylindrical segment of PVC $30 \mathrm{~mm}$ long and $25 \mathrm{~mm}$ in diameter. A metal device was used to standardize the fixation of the mini-implants at $90^{\circ}$ to the resin surface of the specimen. The transmucosal profile and mini-implant head remained exposed.

The specimens were taken to the universal testing machine EMIC DL 2000 (EMIC—São José dos Pinhais/ PR, Brazil) and fixed parallel to the ground and perpendicular to the direction of the applied force. The testing machine was connected to Tesc model software version 3.04 (EMIC-São José dos Pinhais/PR, Brazil) in the compression test mode, with a 2,000 kgf load cell at a speed of $4.0 \mathrm{~mm}$ per minute. A chisel-shaped active tip was used for the force application on the mini-implant, which acted cross-sectionally toward the mini-implant's transmucosal profile. During the application of force, the head of the mini-implant was supported on a metal device

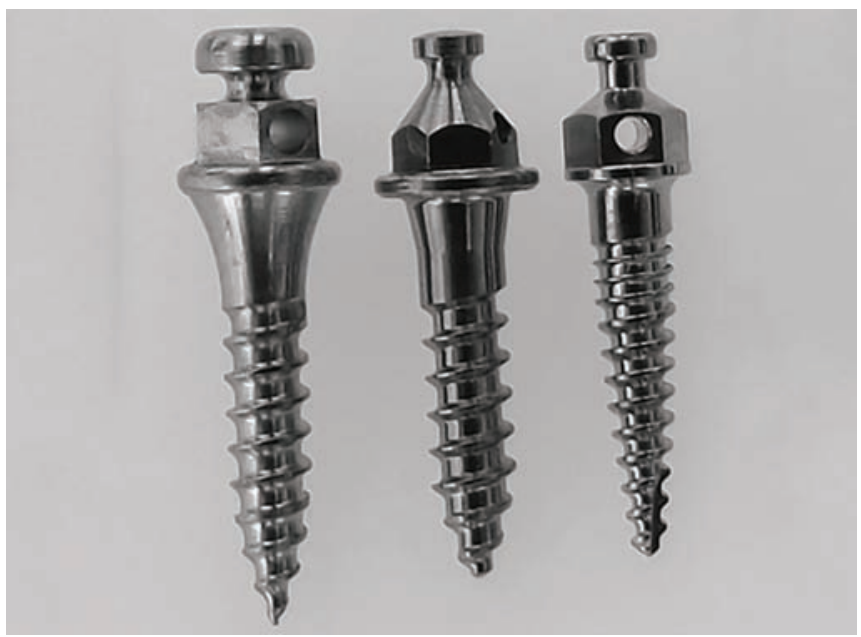

Fig. 1: Orthodontic mini-implants of the groups I, II and III (from left to right) to prevent it from bending without fracture (Fig. 2). The force required for complete disruption of the structure of each mini-implant was applied and recorded.

The Kolmogorov-Smirnov test was used to determine whether the quantitative data presented a normal distribution. A fixed model, single-criterion variance analysis was used to compare the three groups. A significance level of $5 \%$ and test power of $80 \%$ were adopted in all tests. All statistical procedures were performed by a statistician using the Statistica v.5.1 (StatSoft Inc, Tulsa, USA) program.

\section{RESULTS}

The Kolmogorov-Smirnov test showed that the quantitative data had a normal distribution so, the results were analyzed in terms of the mean and standard deviation.

The numerical results showed that group I demonstrated the greatest fracture resistance, followed by groups II and III. However, comparative statistical analysis between brands revealed no statistically significant differences (Table 2).

\section{DISCUSSION}

The use of mini-implants has the primary objective to help the orthodontics movement with greater control with a minimum undesirable counter movements. ${ }^{20}$ The current study was proposed because the transmucosal profiles of different brands of mini-implants have varying measurements of length and diameter. However, our results supported the null hypothesis, as there was no statistically significant difference between the mean fracture resistance values of the three groups tested.

In a previous study, Reicheneder et $\mathrm{al}^{21}$ evaluated 50 mini-implants of five different trademarks. These authors demonstrated that a torque load applied during insertion of the mini-implant could cause premature

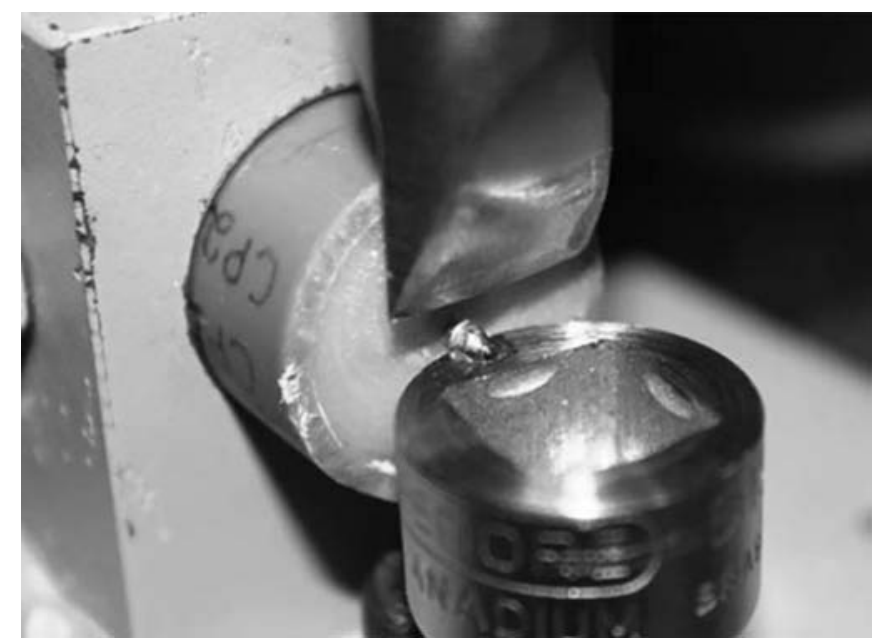

Fig. 2: Positioning of the specimen in the testing machine 
Table 1: Characteristics of the mini-implants

\begin{tabular}{|c|c|c|c|c|c|c|}
\hline Groups & Diameter (body) & Length (body) & Length (cross profile) & Diameter (cross profile) & Reference & Manufacturing batch \\
\hline I & $1.5 \mathrm{~mm}$ & $6 \mathrm{~mm}$ & $2.0 \mathrm{~mm}$ & $1.90 \mathrm{~mm}$ & 37.10 .201 & 1685946 \\
\hline II & $1.6 \mathrm{~mm}$ & $6 \mathrm{~mm}$ & $1.0 \mathrm{~mm}$ & $1.77 \mathrm{~mm}$ & РОТ 1616 & 20040221 \\
\hline III & $1.5 \mathrm{~mm}$ & $6 \mathrm{~mm}$ & $1.0 \mathrm{~mm}$ & $1.50 \mathrm{~mm}$ & 99516199 & 128011 \\
\hline
\end{tabular}

Table 2: Fracture resistance (N), standard deviation (SD) and minimum and maximum values

\begin{tabular}{llllll}
\hline $\begin{array}{l}\text { Groups } \\
\text { Force/ } \\
\text { mean }\end{array}$ & SD & $\begin{array}{l}\text { Minimum } \\
\text { value }\end{array}$ & $\begin{array}{l}\text { Maximum } \\
\text { value }\end{array}$ & $\begin{array}{l}\text { Comparison } \\
\text { (ANOVA) }\end{array}$ \\
\hline I & $172.03^{\mathrm{a}}$ & 25.59 & 131.80 & 197.76 & \\
II & $162.35^{\mathrm{a}}$ & 30.81 & 108.69 & 205.68 & $\mathrm{p}=0.071^{\text {NS }}$ \\
III & $139.69^{\mathrm{a}}$ & 42.99 & 90.20 & 224.45 & \\
\hline
\end{tabular}

Values with the same letter and NS are not statistically significant difference.

mechanical weakness, with severe plastic deformation, and thus a risk of fracture under subsequent bending loads. ${ }^{21}$

The lowest fracture resistance values found in this study were higher than the highest constant flexural strength used, on average, in clinical orthodontic treatment of $400 \mathrm{gm}$. These data seem to indicate safety in the use of these devices. However, it should be noted that during orthodontic treatment, the bending force on the mini-implant is only one of the forces used, and the current study did not evaluate insertion and removal forces. These various applications of force with the use of these materials can cause stress and contribute to their rupture. ${ }^{21}$

In another study, ${ }_{13}^{13}$ the flexural strength and fracture resistance of 75 mini-implants divided equally between five different brands were evaluated, including SIN brand mini-implants. These authors demonstrated that the group composed of SIN mini-implants achieved the highest mean force required to fracture under bending among the tested groups, reaching values of $476.06 \mathrm{~N}$ or $48.54 \mathrm{kgf}^{13}$ In the present study, a fracture resistance value of $162.35 \mathrm{~N}$ was obtained for mini-implants of the same length and diameter and the same brand, corresponding to group II, and this higher value may be related to the different methodologies employed. In the above-mentioned survey, the mini-implants were inserted into cortical bone and may have suffered from fatigue, thereby reducing their resistance to fracture, whereas in this work, the mini-implants were embedded in acrylic resin, with no stress on insertion into the specimen. Another difference was the metal support used to facilitate the tests in this study. The aforementioned study also concluded that the shape of the mini-implant was directly related to its resistance. ${ }^{13}$

Other studies comparing mini-implant insertion torque, removal torque and fracture have also revealed that fracture resistance may be influenced by the design of the mini-implant. ${ }^{12,15,22}$ The mini-implants evaluated in this study had different body types; the bodies of the mini-implants in groups I and II were of a predominantly cylindrical type with a tapered tip, while the miniimplants in group III were tapered, with a reduction in diameter from the transmucosal profile toward the tip. However, the methodology of the current study, in which the mini-implants were embedded in acrylic resin and not inserted into bone, did not allow us to evaluate whether this difference somehow influenced the results.

In this study, group I mini-implants, which had a larger mean transmucosal profile diameter and length, achieved the highest mean fracture resistance. However, this difference was not sufficient to cause a statistically significant difference in the final result after comparison between the three tested groups.

Factors of a general or subjective nature also contribute to the fracture of orthodontic mini-implants, such as the design of the mini-implant, excessive force application at any stage, noncentric movements in insertion or removal procedures and the inappropriate choice of mini-implant diameter/length for a particular bone density.

To minimize the risk of mini-implant fracture, orthodontists must be careful to observe usage techniques and seek information about the structure and other characteristics of the mini-implant they are using.

\section{CONCLUSION}

According to the methodology used and results obtained, the following conclusions were reached:

- There was no statistically significant difference in mean fracture resistance between the studied groups.

- The transmucosal profile diameter does not seem to be a deciding factor in the choice of mini-implants in regard to fractures.

\section{CLINICAL SIGNIFICANCE}

The mini-implants have been used with frequency in orthodontics and has shown many advantages in orthodontic mechanics. Among its disadvantages, we can mention the fractures that can hinder and delay treatment. This in vitro study found that the new brand named group I had a very satisfactory performance when tested its fracture, allowing the clinician to work securely with them. 


\section{REFERENCES}

1. Al-Amiri A, Tabbaa S, Preston CB, Al-Jewair T. The prevalence of dental anomalies in orthodontic patients at the State University of New York at Buffalo. J Contemp Dent Pract 2013;14(3):518-523.

2. Araújo TM, Nascimento MHA, Bezerra F, Sobral MC. Skeletal anchorage in orthodontics with mini-implants. Rev Dental Press Ortod Ortop Facial 2006;11(4):126-156.

3. Janson M, Sant'Ana E, Vasconcelos W. Skeletal anchorage with implants: daily incorporation of the technique in the orthodontic practice. Rev Clin Ortod Dental Press 2006;5(4): 85-100.

4. Laboissière M Jr, Villela H, Bezerra F, Laboissière M, Diaz L. Complications and risk factors (Trilogy-part III). Implant News 2005;2(2):163-166.

5. Jasoria G, Shamim W, Rathore S, Kaira A, Manchanda M, Jaggi N. Miniscrew implants as temporary anchorage devices in orthodontics: a comprehensive review. J Contemp Dent Pract 2013;14(5):993-999.

6. Rothier EKC, Vilella OV. Orthodontic anchorage with miniimplants: factors of success. Rev Bras Odontol 2009;66(2): 177-182.

7. Barros SE, Janson G, Chiqueto K, Garib DG, Janson M. Effect of mini-implant diameter on fracture risk and self-drilling efficacy. Am J Orthod Dentofac Orthop 2011;140(4):181-192.

8. Elias CN, Guimarães GS, Muller CA. Insertion and remotion torque of mini screw orthodontic implant. Rev Bras Implant 2005;11(3):5-8.

9. Kravitz ND, Kusnoto B. Risks and complications of orthodontic miniscrews. Am J Orthod Dentofac Orthop 2007;131(Suppl 4)43-51.

10. Lima GM, Soares MS, Penha SS, Romano MM. Comparison of the fracture torque of different Brazilian mini-implants. Braz Oral Res 2011;25(2):116-121.

11. Mattos CT, Ruellas AC, Sant'anna EF. Effect of autoclaving on the fracture torque of mini-implants used for orthodontic anchorage. J Orthod 2011;38(1):15-20.

12. Nova MFP, Carvalho FR, Elias CN, Artese F. Evaluation of insertion, removal and fracture torques of different ortho- dontic mini-implants in bovine tibia cortex. Rev Dental Press Ortod Ortop Facial 2008;13(5):76-87.

13. Pithon MM, Nojima LI, Nojima MG, Ruellas ACO. Assessment of flexural strength and fracture of orthodontic mini-implants. Rev Dental Press Ortod Ortop Facial 2008; 13(5):128-133.

14. Squeff LR, Simonson MBA, Elias CN, Nojima LI. Characterization of the mini-implants used to orthodontic anchorage. Rev Dental Press Ortod Ortop Facial 2008;13(5):49-56.

15. Wilmes B, Drescher D. Impact of insertion depth and predrilling diameter on primary stability of orthodontic miniimplants. Angle Orthod 2009;79(4):609-614.

16. Wilmes B, Agamemnon P, Drescher D. Fracture resistance of orthodontic mini-implants: a biomechanical in vitro study. Eur J Orthod 2011;33(4):396-401.

17. Singh S, Mogra S, Shetty VS, Shetty S, Philip P. Threedimensional finite element analysis of strength, stability, and stress distribution in orthodontic anchorage: a conical, selfdrilling miniscrew implant system. Am J Orthod Dentofac Orthop 2012;141(3):327-336.

18. Casaglia A, Dominici F, Pachì F, Turlà R, Cerroni I. Morphological observations and fractological considerations on orthodontics miniscrews. Minerva Stomatol 2010;59(9): 465-476.

19. ASTM F136. Standard Specification for Wrought Titanium 6 Aluminum-4 Vanadium ELI (Extra Low Interstitial) Alloy for Surgical Implant Applications (UNS R56401). ASTM International: West Conshohocken (PA): ASTM International; 2013. p. 5.

20. Naidu DL, Harini T, Prasad CMSK, Lakshimi HV, Lokesh NK, Dharmesh HS. Biomechanical characteristics of microimplant for anchorage in orthodontics: a 3D finite element model study. J Contemp Dent Pract 2013;14(6):1076-1079.

21. Reicheneder C, Rottner K, Bokan I, Mai R, Lauer G, Richter G, Gedrange T, Proff P. Mechanical loading of orthodontic miniscrews-significance and problems: an experimental study. Biomed Tech (Berl) 2008;53(5):242-245.

22. Pithon MM, Nojima MG, Nojima LI. In vitro evaluation of insertion and removal torques of orthodontic mini-implants. Int J Oral Maxillofac Surg 2011;40(1):80-85. 